\title{
Аналитическая модель генерации волоконного лазера в режиме одночастотного самосканирования
}

\author{
И.А. Лобач ${ }^{*}$ С.И. Каблуков, Е.В. Подивилов \\ Институт автоматики и электрометрии СО РАН \\ *E-mail: lobach@iae.nsk.su
}

DOI: 10.31868/RFL2020.187-188

Перестраиваемые лазеры широко применяется в различных областях науки и техники. В большинстве случаев перестройка оптической частоты осуществляется внешним образом с помощью спектральных элементов и драйверов, что существенно усложняет конструкцию лазера. На заре лазерной физики в рубиновом лазере в режиме свободной генерации было обнаружено, самоиндуцированное сканирование (для просторы, самосканирование) оптической частоты генерации без применения специальных перестраиваемых селекторов [1]. Позднее такое поведение лазера было исследовано более подробно и дано качественное объяснение, основанное на пространственном выжигании дыр в усилении вдоль активной среды [2]. Стоячая мода излучения выедать инверсную населенность в местах максимальной интенсивности (пучности), что приводит к ее последующему подавлению старой и появлению генерации новой продольной моды. Подобное поведение лазерной генерации наблюдалось в других типах лазерах с зеркалами с обращением волнового фронта [3]. Для объяснения самосканирования частоты было предложено ряд моделей, которые учитывали особенности свойства материалов используемых зеркал. В частности, было показано [3], что в случае кристалла титаната бария за счет лазерного излучения в нем формируется динамическая решетка показателя преломления. При этом за счет дисперсионных свойств материала зеркала наблюдается отличие длины волны генерации и резонансной длины волны отражения сформированной решетки, что приводит к самосканированию длины волны. Однако скорость сканирования в описанных лазерах была слишком низкой, а временная динамика длины волны имела сложный нелинейной характер, поэтому данное направление не получило дальнейшего развития.

Новый виток развития лазеров с самосканированием частоты произошел, когда эффект был получен в волоконном лазере [4-5]. При этом диапазон сканирования длины волны мог достигать более 16 нм в области 1.06 мкм. В работе [5] впервые было показано, что динамика лазерной частоты напрямую связана с динамикой интенсивности лазера - оптическая частота генерации меняется скачкообразно от импульса к импульсу на величину кратную частоте межмодовых биений резонатора. На основе модели с учетом эффекта спектрального выжигания дыр в коэффициенте усиления (решетки коэффициента усиления) получены качественные оценки на изменения лазерной частоты от импульса к импульсу. Надо отметить, что подобная спектральная динамика наблюдается и в обычных волоконных лазерах на пороге генерации (например, [6]). Следующим этапом развития стало получение одночастотного самосканирования, когда каждый импульс состоит из одной продольной моды с частотным чирпом $~ 1$ МГц [7]. Эти результаты позволили предположить, что помимо решеток усиления важную роль в процессе лазерной генерации играют решетки показателя преломления. При этом амплитуды этих решеток определяются амплитудой продольной модуляции инверсной населенности. Таким образом, можно говорить о формировании ком- 
плексной динамической решётки. В этой же работе без вывода было представлено выражение для инкремента роста некоторой моды в присутствии двух решеток (амплитудной и фазовой), записанных ранее генерировавшей модой лазерного излучения. В работе [8] было проведено математическое моделирование для расчета коэффициента отражения сформированных решеток. Оценки показали, что коэффициент отражения решеток может достигать десятков процентов. Однако эксперименты показали [9], что коэффициент отражения таких решеток не такой большой, как предсказывает моделирование и составляет порядка долей процентов. Также в работе [9] получена спектральная форма отражения комплексной динамической решетки, которая хорошо описывается полученными теоретическими выражениями.

Несмотря на практическую ценность подобных перестраиваемых источников, на данный момент времени нет единой модели для описания работы этих лазеров. Полученные в ходе математического моделирования результаты согласуются с экспериментами, но не позволяют анализировать влияние того или иного вклада на режим самосканирования. Настоящая работа посвящена разработке аналитической модели волоконного лазера с самосканированием частоты с линейным резонатором Фабри-Перо, которая учитывает вклад, как динамических решеток усиления, так и показателя преломления.

Модель основана на взаимодействии двух встречных волн одной продольной моды, описываемом уравнениями связанных волн, с учетом динамических решеток, сформированных излучением выходивших ранее в генерацию мод. Основной упор в модели сделан на описании генерации в случае одночастотного сканирования частоты, который экспериментально исследован наиболее подробно. Одним из результатов работы стали аналитические выражения, описывающие параметры генерации в этом случае. В частотности, получено, что временная форму импульса имеет вид:

$$
I(t)=\frac{A}{\cosh ^{2}\left(t / \tau_{p}\right)},
$$

где $A$ - амплитуда импульса, $\tau_{p}$ - характерный масштаб импульса. В этом случае частотный чирп импульса имеет вид:

$$
\delta v(t)=\frac{-\kappa}{2 \pi n_{0} \tau_{p}} \tanh \left(t / \tau_{p}\right),
$$

где $\kappa$ - коэффициент отношения между фазовой и амплитудной решетками, $n_{0}$ показатель преломления волокна. Более подробное описание самой модели и полученных результатов будет представлено в докладе.

Исследование выполнено за счет гранта Российского научного фонда (проект № 18-12-00243)

\section{Литература}

[1] T. P. Hughes, and K. M. Young, Nature 196, 332-334 (1962).

[2] V. V. Antsiferov, V. S. Pivtsov, et al, Sov. J. Quant. Electron. 3, 211-215 (1973).

[3] M. Lobel, P.M. Petersen, et al, J. Opt. Soc. Am. B. $16219-226$.

[4] P. Peterka, J. Maria, et al, Laser Physics Letters 6, $732-736$ (2009).

[5] Lobach I.A., Kablukov.S.I., et al, Optics Express, 19, 17632-17640 (2011)

[6] S. I. Kablukov, E. A. Zlobina, et al, Opt. Lett. 37, 2508-2510 (2012)

[7] Lobach I.A., Kablukov.S.I., et al, Laser Physics Letters, 11, 045103 (2014)

[8] Peterka P., Honzátko P., et al, Optics Express, 24, 16222 (2016)

[9] R. V. Drobyshev, I. A. Lobach, et al, Opt. Express 27, 21335-21346 (2019) 